\title{
DOS VERSIONES SOBRE PROBLEMAS DE LA MUJER ÁRABE: AL-DU'Ā $\bar{Y} \bar{I} Y$ AL-RĀHIB
}

Por

ANA RAMOS

La narrativa árabe contemporánea es prácticamente desconocida en España, a pesar de que se trata de una parcela literaria que ofrece el doble interés de una calidad artística y de un contenido sociológico, que permite entrever la realidad, injustamente ignorada, del mundo árabe. Por ello, deseo contribuir, aunque muy modestamente, a la divulgación de esta literatura con la presentación de dos relatos - que, según mis noticias, no han sido aún traducidos a ninguna lengua europea - inspirados en el viejo tema de la prostitución femenina y escritos por dos autores que han nacido en regiones muy distintas dentro del mundo árabe: Túnez y Siria.

El relato corto, por su misma estructura, es particularmente sensible a los problemas políticos y sociales, que refleja y analiza; entre estos problemas, los que afectan a la mujer, como elemento marginado de una sociedad enferma, resultan obsesivos para aquellos escritores que escogieron este género como medio de expresión y de denuncia, especialmente después de que el realismo se impuso en la narrativa árabe. Se puede afirmar que, durante los últimos veinte años, no se ha publicado una sola colección de cuentos en la que al menos uno no esté consagrado al problema de la condición femenina en la nueva sociedad árabe. La mujer, como personaje literario, ha tenido un lugar destacado en la narrativa árabe de todos los tiempos; sin embargo, como problema social, no se ha reflejado en la literatura hasta el momento en el que el mundo oriental contemporáneo se enfrentó con el mundo occidental (1).

Cuando el ensayista egipcio Qāsim Amin, influido sin duda por precursores como Muhammad ${ }^{\circ}$ Abduh y Ŷamāl al-Din al-Afgãnī, publica en $1899 \mathrm{La}$ liberación de la mujer (Tahrir al-mar'a), al menos un sector restringido de la sociedad árabe considera por primera vez la promoción de la mujer a través de la educación. Cultura deja de ser sinónimo de perdición y mujeres que han podido acceder a ella - Malak Hifni Nāsif (Bahitat al-Bādiya) en Egipto o Widād al-Sakākīni, en Siria, por ejemplo - continúan la obra de Oāsim Amin y comienzan una larga lucha contra los prejuicios sociales para conseguir que la joven, por medio de la instrucción, se ponga en condiciones de afrontar un nuevo tipo de vida. La práctica totalidad de los narradores se encuentra obligada a tratar los problemas de la mujer, aunque la mayoría no se sienta feminista, para convertirla en objeto de análisis intelectual, del que concluyen enseñanzas. A 
una primera etapa romántica, en la que la mujer aparece idealizada - recuérdense las heroínas sublimes en la obra de Tăha Husayn - sucede una etapa realista en la que el narrador se siente fuertemente comprometido con el concepto de justicia social y toma conciencia de la marginación femenina, $y$, si bien comienza a intuir la importancia de la sexualidad en la sociedad, ni siquiera inicia una tentativa de liberación sexual de la mujer; las virtudes femeninas siguen siendo inamovibles.

Cuando son mujeres las que escriben, sienten una especial predilección por tratar temas relacionados con ellas mismas, ya que se sienten particularmente capacitadas para ello por la doble perspectiva que le ofrecen la toma de conciencia general y las experiencias directamente vividas. Es curioso comprobar como por una posible reacción contra la tradición, que tan injustamente la ha tratado, la escritora siente un especial gusto por escandalizar - la dura acusación de la libanesa Layla Bacalbakkī contra su propia madre en Yo vivo (Aná ahyā) es buen ejemplo de ello-. La literatura femenina -en cuanto que está escrita por mujeres - corre paralela a las reivindicaciones feministas - que en su primera época son particularmente activas en Egipto - y a partir de los años cincuenta se hace eco de los problemas laborales de las trabajadoras.

Sin duda la prostitución es uno de los principales problemas sociales que afectan a la mujer y la marginan. También es un tema clásico de inspiración literaria, por el que los narradores han sentido siempre una gran predilección. La mujer pública se presenta en los relatos como víctima involuntaria, por ello el narrador se siente en un papel de protector $\gamma$ analiza las causas que motivaron "la caída", así como sus consecuencias.

Los dos relatos, cuya traducción presento aquí, analizan, desde dos ángulos muy diferentes, las circunstancias que forzaron a sus respectivas protagonistas a ejercer la prostitución.

${ }^{\mathrm{C}}$ Ali al-Du'āît, autor del relato titulado El secreto de la séptima habitación. nació en Túnez a principios de este siglo, en 1909. Su formación bilingüe árabe-francesa se desarrolló en una etapa durante la cual la literatura tunecina luchaba entre dos culturas: la nacional, con su bagaje heredado, y la colonizadora, que en cierto modo se había impuesto a la primera. Al-Dúāŷ̀T, que en su primera etapa escribió en lengua francesa - especialmente poesía -, pronto opta por escribir en su lengua materna, fascinado por el ambiente popular de los barrios antiguos de la capital tunecina, a cuyos habitantes consagra lo mejor de su producción cuentística. Se tra ta de un autor realista, mucho más preocupado por el contenido social de sus relatos, que por la estética de su exposición.

La desgraciada protagonista de E/ secreto de la séptima habitación, escoge por su propia voluntad la vida que se suele llamar fácil; el autor no desea presentarla como un ser amorfo, sin personalidad, pero, en la linea de Qāsim Amin, denuncia la nefasta tradición de enclaustrar a la mujer, desde que alcanza su pubertad, como causa principal de su equivocada decisión.

Como el ensayista egipcio, Al-Duª̄ŷi propone la educación de los jóvenes - el autor tunecino no hace diferencia de sexo, lo que en su época supone un avance extraordinario - como camino único para enfrentarse, responsablemente, con la vida. $Y$, también adelantándose a su generación, cree necesaria 
una información sexual, gradual y racional para que la juventud pueda comprender el amor.

Hāni al-Rāhib, el autor sirio de Regresaron ambos, mantiene, ante el mismo tema, una posición muy distinta. Bilingüe como Al-Duª̄ŷT, su influencia extranjera es anglosajona. La generación a la que pertenece - nació en 1939no está tan preocupada por los temas referentes a la educación como por aquéllos que se relacionan con las estructuras político-sociales; de hecho Hānī al-Rāhib sólo concibe la literatura como un compromiso revolucionario que ayude a cambiar una sociedad enferma desde sus cimientos. Eso no impide que sea uno de los mejores narradores en lengua árabe de la actualidad, por la belleza de su lenguaje y su perfecto dominio de la técnica.

"La Princesa", principal personaje de Regresaron ambos, es una víctima de la injusticia social. Ella no escoje su situación, sino que actúa como una marioneta manejada por su padre, que tampoco es responsable de sus actos. La visión marxista de la sociedad, que domina toda la obra de Hañ al-Rāhib, está representada en este relato, duramente realista y a la vez simbólico. El símbolo es un arma certera en manos de este autor, que lo maneja con verdadera maestría, dejando en el lector un extraño desconcierto y un indudable placer estético. No me puedo sustraer a la tentación de resaltar la bella imagen con la que, en cierto pasaje de su relato, expresa el autor la grandiosa crueldad del combate: «Aquel día la sangre corrió en abundancia, se mezcló y se desparramó bajo el sol como un tapiz rojo"s. Imagen que repite, palabra por palabra, al describir la escena en la que unos corderos son sacrificios públicamente para festejar el generoso donativo con el que "La Princesa" compra el homenaje de aquellos mismos que en otros tiempos la dejaban morir de hambre y la arrojaron del pueblo.

\section{El secreto de la séptima habitación (1) Relato corto de ${ }^{c}$ Alĩ al-Dưāŷĩ}

Habíamos utilizado los más diversos trucos para sacar al doctor de su hermetismo. Por fin dijo:

-El secreto profesional me impide revelar los asuntos de mis clientes; sin embargo, os voy a contar la historia de uno de ellos, por si podéis extraer alguna enseñanza. Solamente omitiré, por ética profesional, los nombres de sus protagonistas y el lugar donde se desarrollaron los hechos.

Continuó diciendo:

- Muchas veces he oído contar fábulas maravillosas, que hablaban de hechos extraordinarios, de genios y de demonios. Ya dijo nuestro poeta Sakälīii: "He creído en los milagros, cuando salen de tu boca, madre". Os digo es to porque un cuento, que nuestra vieja cocinera contaba ayer a los niños de casa; me ha hecho recordar esta historia.

Uno de nosotros pregunto:

- ¿Qué cuento es el que contaba la vieja cocinera? 
- Es la historia del hechicero que raptó al hijo del sultán y voló con él hasta un palacio encantado donde había siete habitaciones de oro, plata, marfil y ébano. El hijo del sultán tenía permiso para entrar y hacer cuanto quisiera en todas ellas, excepto en la séptima, que le estaba prohibida. El hechicero juró que le mataría si tan sólo intentaba introducir la llave en la cerradura.

Calló el doctor dejándonos con la intriga de conocer el final de la historia; sin saber si el hijo del sultán sintió o no curiosidad por conocer lo que encerraba la habitación misteriosa. Limpió los cristales de sus gafas, encendió un cigarrillo y prosiguió su relato:

- Hace unos años traté en mi consulta a una mujer que padecía una enfermedad crónica, que la obligaba a invectarse a diario durante todo un mes. Hubiera resultado hermosa si no fuera porque la enfermedad había deformado su labio inferior. Era... ¿cómo os diría?, una "mujer alegre", ya me entendéis, uligera", eso es, ¿no llamamos delicadamente "ligeras de cascos" a las que son como ella? Como os iba diciendo, a causa de su tratamiento pasaba por mi consulta una vez por semana. Me acostumbré a ella y a su conversación y no me conmovía gran cosa cuando la pobre mujer me contaba las desgracias que la abrumaban, ya que había perdido sus rentas y parte de su capital. Por ello la atendía gratuitamente $-y$ no os lo digo por vanagloria -, la verdad es que me sentía atraído por ella sin saber por qué. A veces me preguntaba a mí mismo cuál habría sido el motivo que impulsó a aquella desgraciada a llevar esa licenciosa y triste vida. Solía imaginármela en el papel de ama de casa, madre de un montón de chiquilios y esposa de un hombre honrado.

Finalmente se curó y las marcas de su “inoportuna» enfermedad desaparecieron por completo.

Cierto día vino a visitarme para darme las gracias por el interés que había mostrado por ella y me regaló una pitillera de nácar con incrustaciones de plata, ya que había observado que yo fumaba mucho. Acepté el obsequio, porque me asombró el buen gusto que había mostrado al escogerlo.

- Es lo menos que le podía ofrecer - me dijo.

-Si es así - contesté sonriendo-, ¿por qué no me hace un regalo más?

La pobre se quedó confusa, sin saber a qué me refería; entonces, avancé hacia ella y la saqué de su asombro diciendo: «No, no. No se trata de eso... lo que yo deseo de usted es algo más precioso que un regalo material. Lo que quiero es que me descubra parte de su secreto... del secreto de su vidan.

Pareció no comprenderme, por lo que añadi: «Me gustaría saber, si es posible y si sus recuerdos no la atormentan, el motivo que la impulsó a llevar esta vida, quiero decir..."

Se le llenaron los ojos de lágrimas y dirigió la vista a los opacos cristales de la ventana, como si viera en ellos, a través de sus lágrimas, una pantalla en la que se fuera proyectando la película de su infancia y de su juventud, con sus penas y alegrias.

- No se preocupe - le dije - Ilore, las lágrimas nos limpian de nuestras 
culpas; mientras queden lágrimas en nuestros ojos, no tenemos de qué préocuparnos.

Mientras decía esto con voz temblorosa, se me iba empapando la frente de sudor. $Y$ es que las lágrimas me infunden respeto..., aunque sean las lágrimas de una mujer de "vida alegre».

- Jamás hubiera imaginado - dijo - una vida como la que llevo ahora. Si de niña la hubiera vislumbrado en sueños, me habría despertado horrorizada.

"Creci en un hogar tradicional. Mi padre - que en Gloria esté - era un hombre de otra época, con un sentido estricto del honor y celoso guardián de las antiguas costumbres populares. Era terriblemente serio, adusto, exageradamente piadoso. No nos permitía salir de casa, ni para ir a los baños o a las casas de los parientes más cercanos. Los únicos hombres que conocíamos eran él, mi abuelo y mis tíos paterno y materno; tampoco conocíamos a más mujeres que a mi madre y a su hermana. Tanto mi hermana - que es dos años menor que yo - como yo misma, ignorábamos todo lo que se refería al mundo que había más allá de las paredes de nuestra casa. Por otra parte, nunca nos puso la menor traba en materia de comida, vestidos, joyas o cosméticos.

"A estas alturas no sé si llorar o reir por aquella forma de vivir. El caso es que llegué a los diecisiete años sin saber nada acerca de los hombres."

Uno de nosotros interrumpió al doctor:

-Pero ¿qué relación existe entre las inyecciones, la pitillera de nácar y el secreto de la séptima habitación?

Todos nos echamos a reír. El doctor cogió la mano de su impaciente amigo, le tomó el pulso y cuando comprobó que ni tenía fiebre ni nos podía contagiar otra cosa que la risa, dijo:

- Pasé más de una hora escuchando.e sta historia, permitiendo que mi interlocutora pasara continuamente de un tema a otro. Todos sabemos que las conversaciones de las mujeres son incoherentes y que mezclan una charla sobre el tiempo con lo que han oído en casa de la modista o en la peluquería; por ello es prácticamente imposible escucharlas en sólo diez minutos. Cuando termine con mi historia te recetaré un calmante para los nervios, porque, como se suele decir, "si callas, revientas" (1).

El doctor volvió a su relato:

-A veces - continuó diciendo la mujer - nuestra madre hablaba del matrimonio y nosotras nos lo imaginábamos a nuestro antojo. Sabíamos que mi padre se había casado con mi madre y que ésta nos había traído al mundo, pero ¿cómo?, ¿por qué? Estas preguntas jamás nos las aclaró mi madre, que incluso nos prohibió presenciar el parto de Morgana, nuestra gata, y nos encerró en un cuarto hasta que el acontecimiento concluyó.

"Viviamos en una casa antigua de un solo piso en cuya azotea había una habitación en la que estaba absolutamente prohibido entrar. Nunca vimos a nuestros padres dirigirse a aquella estancia abandonada. La prohibición encendió en nosotras la llama de la curiosidad y dejábamos volar la imaginación, su- 
poniendo que aquel cuarto maldito estaba lleno de tesoros y de secretos; sin embargo, no nos atrevíamos ni a pisar los escalones que conducían a él, por temor a las consecuencias.

"Cierto día de verano, a la hora de la siesta, cuando mi padre se hallaba ausente de la ciudad, y mi madre estaba de tertulia en sus habitaciones, mi hermana y yo decidimos desobedecer a nuestros padres y subir a aquella habitación, que nos tenía fascinadas. Acordamos que entraría primero una, mientras que la otra hacía guardia. A mi me tocó ser la primera. La cerradura no tenía llave, únicamente había un cerrojo oxidado, que descorrí con cierta dificultad Abrí la puerta y me encontré en un cuarto pequeño, cuadrado, con las paredes cubiertas por una mezcla de polvo y telas de araña. Mientras mis ojos se iban acostumbrando a la penumbra y mis pulmones a la pesadez del ambiente, observé que sobre la puerta había un ventanuco en forma de cuello de botella, sin reja de hierro, ya que al parecer había sido prácticado con el único fin de permitir la iluminación y la ventilación del cuarto y... también para perderme a mí.

"Naturalmente, me faltó tiempo para encaramarme hasta allí y atisbar 10 que los gruesos muros no podian ya ocultar a mis ojos. iY vi!

"La casa que estaba situada frente a la nuestra se utilizaba para... "la disipaciónn. Bueno, esto lo supe más tarde, porque en aquel momento lo único que vi a través del ventanuco fue una cortinilla y un lecho tendido sobre el suelo en el que yacian un hombre y una mujer. Junto a ellos habia una mesa y sobre ella botellas, vasos, una raja de sandía y hielo.

"No bajé de allí hasta pasada más de media hora, por más que mi hermana insistía reclamando su turno. Aquella media hora supuso para mi toda una eternidad y durante ella lo aprendí todo.

"Volví una y otra vez al cuarto de la azotea hasta que mi madre se percató de ello y me pegó. También se enteró mi padre y me golpeó brutalmente. Hasta que, una noche, me eché una toalla por la cabeza y me fui... a la casa de enfrente."

El doctor guardó silencio, $y$ uno le preguntó:

$-¿$ Qué paso con la hermana pequeña?

Y otro:

- ¿Por qué no había tapiado el padre de las jóvenes aquel ventanuco? ¿Acaso no lo consideró importante?

El doctor no hizo caso de estas preguntas, que consideraba al margen de la historia. Parecía que iba a hablar sobre la reacción que puede producir en el alma de la gente joven la impresión de conocer, de pronto y a la vez, ciertas cosas que deben ser aprendidas poco a poco. IY bien que nos habría gustado que lo hiciera!, pero, de pronto, recordó que tenía un compromiso y acudió a él cantando entre dientes una canción muy conocida que empieza asi:

"El amor, la juventud...". 


\section{Regresaron ambos (1)}

(Relato corto de Hānĩ al-Rāhib)

- ¿Qué ha sido de Muhammad Maryašad?

-Está en la capital.

- ¿Y de Șuwaylah Abū Șuwaylah?

-Está también en la capital.

- IEn la capital, en la capital! ¡Todos en la capital! ¿Y en qué trabajan?

-En la Administración.

- ¿Y Darwīš Zuhayr? ¿También está en la capital?

-No. Ese está en Tartūs, el puerto. baja?

- \Vayal „Por lo menos hay uno que no está en la capital! ¿Y en qué tra-

-En la Administración. Pero, lqué sorprendido pareces! jcomo si no estuvieras enterado de nada!

En aquel momento, de un callejón sin pavimentar salió corriendo un grupo de chiquillos en dirección a la calle principal. Iban corriendo, sin decir nada, llevando en las manos ramas frondosas o desprovistas de hojas, envueltas en papeles de colores, con banderitas atadas en los extremos, de tonos blanco, verde y rojo. Iban gritando sin decir nada. Llenaron la calle de polvo y desaparecieron.

$-¿$ Qué hora es?

-Las seis y siete minutos.

-Faltan cincuenta y tres minutos para que llegue.

- Dicen que ni los príncipes ni las princesas se preocupan demasiado de cumplir sus promesas.

-Ésta no es de la clase de princesas que tú conoces.

- Las habrá de muchas clases, pero todas son iguales.

- Te equivocas. Esta princesa cumplió cientos de promesas cuando estaba en la capital. Cumplía con quienes acudian a la cita, previamente concertada, y si alguno se retrasaba, salía ella misma a su encuentro.

El camarero se acercó a ellos, recogió las tazas de café vacías, presentó la cuenta y se fue.

Se ponen en pie. Uno de ellos es un hombre de unos cuarenta años, de expresión adusta. Coge la muleta que está apoyada en una silla próxima, la ajusta 
bajo su axila y sale de detrás de la mesa, empujando la muleta con la pierna y apoyándose en ella.

Los dos hombres echan a andar por el borde de la calle, que se supone es una acera. El cojo camina con dificultad a causa de los baches, de los montones de tierra y de los desperdicios. Se fijan en los árboles y en las casas, mezcla incongruente de adobes, de madera, de piedras, de cemento y de trapos viejos. Hay algunas casas para personas, para chinches y para animales; otras están hechas para personas, fuentes y jazmines. También hay cobertizos levantados y a medio levantar, árboles tronchados por todas partes y montones de tierra $y$ de ladrillos, que en su día fueron edificios.

De todas las casas salen niños de distintas edades, que corren velozmente, sin parar, sin decir una palabra. Uno tropieza - ha salido sin terminar de calzarse - y grita: "No corras, espérame».

- ¿No ves qué devastación? Pues aquínació Sucdà, o "La Princesa", como la llamáis ahora.

- ¿Sưdà? ¡Se llama Sacäd!

- ¿Cambió su nombre después por Sacãd. Hacía el número once de los hijos de Umm Fãniyya y de Ab Sikkîr. La madre estaba destrozada. iFigúrate! Once hijos de los que una tercera parte padecía enfermedades crónicas, sobre todo raquitismo, por el hambre. Un hambre como tú no has conocido jamás. Un hambre de esas que impulsa al que la siente a coger cáscaras de sandía para comérselas. Naturalmente y por desgracia, en la aldea no había cubos de basura, de modo que no se encontraba una fuente fija de desperdicios para comer : Cuando $\mathrm{Su}^{c}$ dà contaba dos años, su padre se volvió a casar y siguieron llegando hijos; la segunda mujer era saludable, fuerte y fértil. Al cumplir Sucdà diez años el número de criaturas alcanzaba la veintena - tres partos fueron dobles-, por lo que no había suficientes cáscaras. Empezaron, por las noches, a ir a los cafés, a las huertas para coger fruta y a los campos a por cereales y legumbres. Después entraron en las casas y cogían todo tipo de provisiones: vestidos, zapatos, gallinas, huevos, aceite, manteca, aceitunas, e incluso el forraje de los animales. Y así iban tirando.

- ¿Qué hizo la gente del pueblo?

- No robaban a todos; solamente a aigunos. Tú fijate bien en esta calle: ese edificio valdrá unas cien mil libras y aquella villa otras cien mil; en medio de ambos no hay más que casuchas, cobertizos, chabolas de tierra y toda esta desolación. Dime, si hubieras teriido hambre, ¿cuál de estas casas habría escogido para saquearla, sin pensar en quiénes habia dentro? Entonces y ahora, to do sigue igual. No es que ellos se sintieran solidarios de nadie -en realidad, eran enemigos de todos, con excepción de aquéllos que, lo mismo que ellos, habian llegado al más bajo nivel - , sino que cuanto deseaban, lo encontraban en las casas de piedra. De todos modos, al cabo de un año, de un año y dos meses, todos estaban contra ellos. Ya conoces a las gentes de los pueblos y las peculiares leves que regulan sus conciencias: no importa a quién, lo que importa es que robas. Por eso, todos se les pusieron en contra. Primero, murmuraron y cuchichearon hasta que llegaron a un veredicto general $y$ empezaron a perseguirles. Todo esto sucedió mucho antes de que tú nacieras, por eso ahora no te lo puedes creer. Durante dos años la doble familia lievó una vida errante. Natural- 
mente, la mitad de los hijos de la segunda mujer murieron - jterrible gesto de compasión por parte de la Naturaleza, la muerte!-. En toda la historia de la humanidad no ha habido nadie en el mundo que haya pasado tanta hambre como la que pasaron ellos. Una criatura ca'a al suelo, así de sencillo, encima de un trapo, de una esterilla, de cualquier cosa y permanecía allí durante días, abandonada. Se le consumía la carne, se le secaba la garganta y se moría. Entonces, los demás se iban - si no se habian ido ya - Sus verdaderos asesinos eran los señores que destinan a sus campesinos a que tengan este fin.

\section{- ¿Y a dónde fueron?}

- Eso nadie lo sabe, se fueron, eso es todo y estuvieron ausentes varios años. Después reaparecieron todos por aquí. Unos pisando firme, otros junto a bandidos y fugitivos, algunos estaban en la cárcel y otros unidos a la revolución. El caso es que reaparecieron. Todos, menos Sucdà, "La Princesa", que se había desvanecido.

Al final de la calle, donde se inicia un camino que serpentea entre las montañas, los dos hombres se detienen. El cojo saca la muleta de debajo de su axila y se sienta en una piedra. Su compañero, conmovido, le mira en silencio, con las manos prestas para ayudarle. En aquel momento, atraviesa el aire el tumulto de unos gritos alegres, a la vez que se oye el rugido atronador de un camión, que circula por el camino de tierra. Al avanzar, levanta una nube de polvo, en medio de la cual los dos amigos distinguen cinco corderos bien cebados, seguidos de diez hombres, portadores de largos y fuertes cuchillos, que ríen mostrando sus dientes blancos y carcomidos. Antes de que la nube de polvo se disipe aparece por el camino un grupo de niños y de muchachos que van corriendo tras el camión con la lengua fuera por la carrera y en silencio, debido al duro esfuerzo. El hombre cojo hace ademán de hablar, pero permanece callado. Siguiendo a la primera caravana, aparece un segundo vehículo del que se oye el estruendo que causan sus piezas interiores al golpear contra la chapa. Unos segundos antes de que pudieran distinguir el coche entre la nube de polvo, llega hasta los dos hombres un gran alboroto, producido por los cortos y atemorizados chillidos de unos gallos.

- ISon de "La Princesa"! flos dos coches, el primero y el segundo!

- ¿De "La Princesa"? ¿Ese millar de gallos es de "La Princesa"?

- Y también los cinco corderos. Todos serán sacrificados cuando ella descienda del coche para trasladarse a la litera.

- ¿A la litera?

-Sí, a la litera, a la usanza de las mujeres árabes principales.

- ¿Se va a bajar del coche para subir a una litera?

- iNi que fueras extranjerol El coche pesa mucho para ser llevado a hombros. La litera es mucho más ligera y aún así, cuando se carga con ella se rompen los riñones...

- ¿De dónde son ésos? ¿Son gente de la aldea? 

más.

-Si, son de la aldea y no hay uno solo que no haya cogido mil libras o

- IMit libras o más! ¿Y cuántos son?

- ¿Cuántos? Dos mil, tres mil, hasta puede que más. Dicen que «a Princesan ha distribuido tres millones. Hay quien ha recibido cincuenta mil e incluso cien mil. Todos menos sus parientes.

- iTres millones! ¿Y tú? ¿Cuánto has cogido?

- ¿Yo? Si hubiera estado aquí, también habría cogido algo.

-ITres millones!

El hombre cojo se apoya en su muleta y se levanta. La vuelve a ajustar bajo su axila y echa a andar por el mismo camino que siguieron los dos coches. Su compañero se une a él, acomodándose a su paso.

- ¿Dónde se desvaneció "La Princesa"?

- Nos perdimos juntos en Beirut los tres. Su padre la había llevado allá. Por mi parte, habla renunciado a encontrar trabajo aquí, entre el temor y la pobreza. Cogí a mi tío y nos fuimos a Beirut. Por aquel entonces $S u^{c}$ dà tenía doce años. La habían vendido en Alepo, pero consiguió escapar. Pasábamos los días en la oficina de empleo; su padre quería encontrar trabajo, el que fuera, y para $\mathrm{Su}^{\mathrm{c}}$ dà buscaba una familia que la aceptara como sirvienta. Olvidé decirte que, a pesar de sus doce años, "La Princesa" habla hecho grandes progresos como mujer. Era muy bella; impresionantemente bella, con ese tipo de belleza que produce alegría y felicidad, por su ingenuidad y su candor. La suya no era una de esas beflezas ardientes y excitantes.

- Y todavía es muy guapa. Yo creo que la gente se congratula más por su belleza que por su dinero. Si hubiera sido poco agraciada, cogerían su dinero y se reirian de ella. Sin embargo, ríen para ella, sinceramente. Por supuesto, también aprecian la belleza de su corazón. ¡Repartir su dinero entre todos después de lo que habían hecho, unos más y otros menos, con ella y con los suyosi Porque la verdad es que no hay uno solo que pueda decir: "'La Princesa" no me ha dado nada... Pero, continúa ¿qué sucedió en Beirut?

- ¿En Beirut? Bueno, ya sabes cómo se inicia la carrera de una muchacha

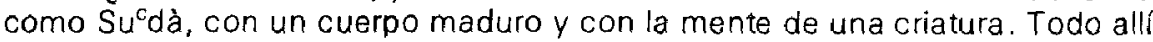
está dispuesto para explotar semejante mina y su padre..., su propio padre, la puso en este camino. El único problema de aquel hombre era que no quería que la niña perdiera su virginidad. En este punto se mostraba intransigente hasta la locura. La verdad, no sé bien por qué. Posiblemente quedaría en lo más profundo de su ser algún lugar al que aún no hubiera llegado la degradación. Es posible también, que viera en la virginidad de su hija, mientras permaneciera intacta, algo de su propia dignidad o que quisiera casarla o que... bueno, ya sabes..

-Ya sé ¿qué?

-Pues que quisiera casarla... mediante una cantidad estipulada. 
- No entiendo nada. ¿Prostitución y virginidad? No me parece que sea una buena combinación.

-No. No he dicho prostitución. Eso vino dos meses después de haber inscrito su nombre en la oficina de colocación. Es que allí, en la capital, existen ciertas oficinas que tienen una doble función, jvamos, que hacen de intermediarias! La verdad es que eres un hombre de lo más extraño. Pareces extranjero. ¿No te he dicho que una bella muchacha desapareció de su pueblo y que en su lugar apareció una fortuna?

Se oye un golpe de tambor, después dos. Un ruido enorme aumenta por momentos y se va haciendo general. Los tristes sonidos de las flautas de los gitanos se mezclan con el redoblar de los tambores, con un ritmo pagano que hace latir los corazones. Durante algunos instantes se oye una música que estimula y tranquiliza a un mismo tiempo. La violencia explosiva de los redobles del tambor, unida a los suaves lamentos de las flautas incitan a la danza y al libertinaje, a una paz interior y al desenfreno externo. La insistente monotonía de aquella música se mete en el alma como agujas de láudano y el tumulto se convierte en vértigo.

Mientras suena la música, se va concentrando en la atmósfera nube de humo negro, a la que sustituyen, volando por el aire, unas lenguas de fuego, procedentes del incesario de "La Princesa", que se suceden unas a otras. Los dos amigos se dirigen hacia la plaza situada en el extremo occidental del pueblo y alli asisten al espectáculo del fuego, de los músicos y de un millar de gente feliz.

- ¿A quién la vendió?

- Nadie lo supo nunca y hasta hoy, no lo he sabido yo. Por aquella época mis relaciones con ambos eran muy tirantes. Por culpa de su padre. Habían pasado cuatro años y $S u^{\complement}$ dà se había convertido en una verdadera mujer - para lo que se había estado entrenando, durante cuatro años--. Intenté salvarla, pero por su culpa me vi en prisión. Su padre inventó cierta historia acerca de mi y me detuvo la policía. Fracasé. ¿Qué podía hacer yo? Con semejantes redes se gobiernan ciudades y estados. Nadie se rebela contra ellas, nadie las puede vencer.

Después de aquello, $S u^{c}$ dà buscaba refugio en mí y lloraba entre mis brazos. Siguió viniendo durante algún tiempo, pero en lugar de lamentarse, se reía. Se sentaba en una silla, nos sentábamos los dos, y permanecía así durante una hora o dos, como si aspirara un aroma inexistente, que viniera del exterior o como si viera una cortina protectora, imaginaria, que colgara a lo largo de las paredes. Un día... le propuse matrimonio. Tendría ella entonces unos dieciséis años aproximadamente, pero ya era otra.

- ¿Qué respondió?

-Fue incapaz de dar amor a cambio de amor. Abrió su bolso y sacó todo lo que había en él, trescientas, cuatrocientas... ¡no sél Me ofreció aquel dinero. Así terminamos.

- ¿Qué hiciste?

-Reconozco que tuve una reacción violenta. Desproporcionada incluso 
para mi carácter iracundo. No volvimos a encontrarnos y ahora me arrepiento. No supe comprender que la vida había anulado su capacidad de amar. Pensé que la desgracia acabaría por romper un vínculo tan fuerte como el del amor. Pero eso pertenece al pasado. Lo cierto es que Sucdà desapareció dos meses después por espacio de quince años. Ni la vi nunca ni jamás oíla menor cosa acerca de ella. Tampoco vi a su padre. Lo que está claro es que debió recibir una fuerte suma. Ni siquiera volví al pueblo para no oír nada sobre ella. Y jya ves!, se me ocurrió volver ayer por la noche y me entero de que ella vendría hoy. |Después de quince años!

- ¿Y qué fue de tu vida?

- ¿Después de que ella desapareció? ¿O quieres saber por qué me cortaron la pierna?

- Las dos cosas

-Bueno, la verdad es que las cosas siempre se relacionan unas con otras. En la capital estaban plenamente convencidos de que la situación era estable y de que se seguiría manteniendo asi. Pero habia una actividad tremenda. No supieron darse cuenta de 10 que estaba formándose bajo sus propios pies y mucho antes de lo que hubieran podido imaginar, antes de que se encontraran irremisiblemente hundidos, a causa de la explotación del capital, del turismo, del comercio... lo que era inevitable estalló. Yo trabajaba por entonces en el puerto, desde hacia tres años. Presentíamos que el estallido andaba próximo. ¿Recuerdas la batalla de los Hoteles (Al-Fanādíq?) |Aquella sí que fue una verdadera batalla! IV cómo peleamos en ella! $Y$ de Tell al-Zactar, ¿te acuerdas? Cúando atacábamos la retaguardia del enemigo, mi pierna voló por los aires. Aquel día la sangre corrió en abundancia, se mezcló y se desparramó bajo el sol como un tapiz rojo.

La música se difunde por la plaza situada en el extremo occidental del pueblo por la que todo el mundo anda disperso. Las fogatas iluminan los alargados edificios de la plaza, mientras se elevan los sones de las flautas. Un coche blanco se detiene a la entrada de la plaza, se abren sus cuatro puertas y desciende de él "La Princesa". El caos se hace general. La gente se arremolina atropelladamente. Los más jóvenes corren mientras una brillante litera avanza, sustentada por ocho hombros, y se detiene finalmente en el centro de la plaza. Los cinco corderos, que habían llegado corriendo al lugar donde se encuentra "La Princesa", se detienen también. Los gallos dispuestos para su sacrificio, que aún no han muerto, revolotean por los aires, caen al suelo y asustan a los que les persiguen corriendo. La confusión es total. Se elevan los gritos $y$ las voces, las llamas se hacen más intensas, los que bailan tienen las gargantas contraídas, redoblan los tambores, silban las flautas, los corazones se conmueven... y "La Princesa" se encuentra radiante, satisfecha y feliz.

El primer cordero es derribado; cuatro hombres corpulentos 10 inmovilizan en et suelo y un quinto hombre lo degüella. Del mismo modo son sacrificados el şegundo, el tercero, el cuarto y el quinto. La sangre corre, se mezcla $y$ se desparrama ante "La Princesa" como un tapiz rojo. Con una rama de olivo doble se consigue que la sangre se extienda bien. Cuatro niñas se acercan a "La Princesa", levantan la cola de su vestido y Sucdà empieza a caminar.

Las mujeres hacen albórbolas, que se mezclan con las canciones de las 
comparsas y se oyen vítores y aplausos; las llamas se hacen más vivas y la música suena con más fuerza. "La Princesa" llega a donde está estacionada la litera. Las mujeres la izan hasta ella y unos hombres la cargan sobre sus espaldas.

El cortejo se pone en marcha. Caminan unos tras otros, siguiendo a la litera. Al pasar junto al fuego cada uno coge una rama ardiendo y la lleva levantada, rompiedo la intensa oscuridad... y continúa el desfile. Parece como si el cielo hubiera bajado a la tierra.

Al pasar junto a los dos amigos, el cortejo se detiene. Circulan los comentarios: "¿Será que "La Princesa" quiere saber quiénes son aquellos dos, que no se han unido a los demás?". "¿Qué les ocurrirá?". "¿Estarán enfadados?". "¿Será que no han recibido dinero?».

Los que iban a la cabeza del desfile se acercan a los dos hombres y cesan los murmullos. En medio de un gran silencio la multitud les observa, con ojos expectantes.

- "La Princesa" solicita vuestro homenaje.

- No tenemos nada que ver con vuestros festejos, como tantos otros, que no se encuentran hoy aquí. Decid a "La Princesa" que no se preocupe.

- ¡Pero "La Princesa» os lo pide!

- Pues decid a vuestra señora que, aunque sea princesa, es posible que no pueda encontrar más allá de diez o veinte hombres. Nosotros, sin embargo, con dar una patada en el suelo, tenemos príncipes y princesas a millares.

Terminado el diálogo los comisionados vuetven junto a "La Princesa" con la que intercambian algunas palabras. Su' dà desciende de la litera, recoge con una mano los pliegues de su falda y sujeta con la otra un pequeño bolso. Mientras se dirige hacia los dos amigos suelta el borde de la falda, vacia el bolso del montón de billetes que contiene y vuelve a recogerse los vuelos del vestido.

En un instante determinado le reconoce y se detiene, mientras se desvanece su sonrisa. Es una cuestión de segundos e inmediatamente se vuelve, pero su expresión ya no es la misma. En el momento en que fijó su mirada en la pierna amputada del hombre, la mano, que llevaba extendida, llena de dinero, se le había quedado rígida, como si fuera de piedra. 